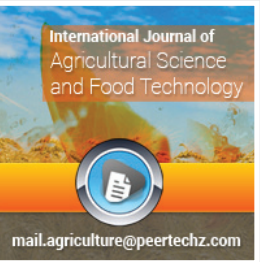

Life Sciences Group

\title{
International Journal of Agricultural Science and Food Technology
}

\section{Dinesh 0 Shah*}

Professor Emeritus, Chemical Engineering and Anesthesiology Departments, Founding Director of Surface Science and Engineering, University of Florida, Gainesville, FL 32608, USA

Received: 25 October, 2018

Accepted: 31 October, 2018

Published: 01 November, 2018

*Corresponding author: Dinesh O Shah, Professor Emeritus, Chemical Engineering and Anesthesiology Departments, Founding Director of Surface Science and Engineering, University of Florida, Gainesville, FL 32608, USA, Email: dineshoshah@yahoo.com

https://www.peertechz.com

\section{Check for updates}

\section{Editorial}

At a Global scale, we are growing as much grain as possible to feed world population and domestic animals. As the world population grows in the coming decades, we may not have enough grain to feed the world population. The limiting factors are land suitable for cultivation or farming, environmental conditions and water available for plant growth/farming. Thus, the goal should be how much grain, e.g. corn or wheat we can grow per gallon of available water? If we focus on available water for agriculture, then evaporation loss from soil is the major mechanism for the loss of water.

We have shown [1], that we can retain more water in soil by layering a hydrophobic or water repellent soil layer ( $5 \mathrm{~mm}$ to 10 mm thickness) on top of normal soil to save as much as $90 \%$ of water lost by evaporation. Not only we retain water in the soil but the retained water can enhance the growth of the plants [1]. This can be achieved for indoor plants or those grown in the green houses. Additional water can be provided as needed by funnels or by drip irrigation in pots or in farms.

Soil consists of millions of fine capillaries formed by the spaces between soil particles. Wettability of the capillary surface controls whether liquid water can reach to the upper surface of soil. Hydrophobic soil layer prevents the transport of liquid water to the soil surface and pushes meniscus below the hydrophobic capillaries. Only water vapor can move through the hydrophobic capillary to the surface of the soil. This is a very slow diffusional process which allows liquid water to stay in the subsurface region of soil. The retained water promotes the growth of the plants [1].

Application of this idea to farmland requires that after sufficient rain has delivered required water to the ground, we spray a biodegradable chemical that can make top surface of the soil (5 to $10 \mathrm{~mm}$ ) hydrophobic. Say after eight or twelve weeks if the soil surface returns to its normal surface characteristics due to the biodegradation of this chemical, then we have succeeded in retaining water for a longer period and thus we have enhanced the growth of plants with much less water usage.

This invention has provided a novel method to reduce evaporation of water from the soil significantly. Research community has to come up with ways to take benefit of the retained water in the soil to enhance the growth of crops. In our lab scale experiments, the results are very promising in that we can grow significantly more corn under identical environmental conditions. This novel method of retaining water in the soil can bring many arid and semi arid or one- rain per monsoon regions under cultivation.

\section{References}

1. Gupta B, Shah DO, Mishra B, Joshi PA, Gandhi VG, et al. (2015) Effect of top soil wettability on water evaporation and plant growth. J Colloid Interface Sci 449: 506-513. Link: https://tinyurl.com/y72osed3 